\title{
SEX DIFFERENCES IN LIMB AND JOINT STIFFNESS IN RECREATIONAL RUNNERS
}

doi: 10.1515/humo-2015-0039

\author{
JONATHAN SINCLAIR ${ }^{1 *}$, HANNAH FRANCES SHORE ${ }^{1}$, PAUL J. TAYLOR ${ }^{2}$, STEPHEN ATKINS $^{1}$ \\ ${ }^{1}$ Centre for Applied Sport and Exercise Sciences, School of Sport Tourism and Outdoors, University of Central Lancashire, \\ Preston, United Kingdom \\ ${ }^{2}$ School of Psychology, University of Central Lancashire, Preston, United Kingdom
}

\begin{abstract}
Purpose. Female runners are known to be at greater risk from chronic running injuries than age-matched males, although the exact mechanisms are often poorly understood. The aim of the current investigation was to determine if female recreational runners exhibit distinct limb and joint stiffness characteristics in relation to their male counterparts. Methods. Fourteen male and fourteen female runners ran over a force platform at $4.0 \mathrm{~m} \cdot \mathrm{s}^{-1}$. Lower limb kinematics were collected using an eight-camera optoelectric motion capture system operating at $250 \mathrm{~Hz}$. Measures of limb and joint stiffness were calculated as a function of limb length and joint moments divided by the extent of limb and joint excursion. All stiffness and joint moment parameters were normalized to body mass. Sex differences in normalized limb and knee and ankle joint stiffness were examined statistically using independent samples $t$ tests. Results. The results indicate that normalized limb (male $=0.18 \pm 0.07$, female $=0.37 \pm 0.10 \mathrm{kN} \cdot \mathrm{kg} \cdot \mathrm{m}^{-1}$ ) and $\mathrm{knee}$ stiffness $\left(\right.$ male $=5.59 \pm 2.02$, female $=7.34 \pm 1.78 \mathrm{Nm} \cdot \mathrm{kg} \cdot \mathrm{rad}^{-1}$ ) were significantly greater in female runners. Conclusions. On the basis that normalized knee and limb stiffness were shown to be significantly greater in female runners, the findings from the current investigation may provide further insight into the aetiology of the distinct injury patterns observed between sexes.
\end{abstract}

Key words: running, sex, limb stiffness, biomechanics

\section{Introduction}

Distance running is a very popular physical and recreational activity that has been shown to be physiologically advantageous [1]. However, retrospective and prospective aetiological research indicates that 19.4$79.3 \%$ of those who engage in running activities will suffer from a chronic pathology over the course of 1 year [2], in which female runners are known to be at greater risk from chronic running injuries than age-matched males [3].

It has been proposed that differences in lower extremity injury susceptibility between sexes are related to the distinct kinetics and kinematics exhibited by female runners in relation to males [4]. Current research indicates that females are twice as likely to experience an injury in relation to running [5-6], though the specific aetiological mechanisms are not well understood. Thus, there are requirements for further examination into the biomechanical mechanisms that may be associated with injury in female runners.

Current clinical research on the aetiology of chronic lower limb pathologies and the mechanics of human locomotion has begun investigating lower extremity limb stiffness. Stiffness, in its simplest form, is a ratio of the force applied and subsequent deformation of a body [7]. During running, the stance limb can be modelled using a spring mass system, where the stance limb reflects

\footnotetext{
* Corresponding author.
}

a linear spring and the runner's body mass is representative of the point mass [8-10]. The limb spring is able to compress and expand during the stance phase as lower extremity joints flex and then extend [11]. With regards to clinical effects, if the limb spring is overly compliant, then overload of the musculoskeletal structures associated with force attenuation may occur. In turn, if stiffness increases, the forces may be increased up the kinetic chain [12-14]. It has been therefore hypothesized that excessive limb stiffness may be linked to an enhanced risk for bone-related injuries whereas insufficient stiffness a risk for soft tissue injury [7, 12, 15, 16].

It has also been proposed that the stiffness characteristics of the lower extremity joints need consideration [7]. Joint stiffness is a reflection of the moment to angular excursion ratio and is modelled as a torsional spring system [12]. Joint stiffness is also clinically important as it can be related to the attenuation of load transmission through the musculoskeletal system $[13,17]$. Increased joint stiffness may also be linked to the aetiology of running injuries as higher stiffness leads to an increased load that must be borne by the joint in relation to a more compliant joint [17-19].

In this regard, sex differences in limb stiffness have also been previously considered. Padua et al. [20] examined sex differences in limb stiffness during a two-legged hopping task. They showed that females exhibited increased limb stiffness but these between-sex differences were eliminated when the data was normalized for body mass. Granata et al. [21] showed that females were 
associated with increased limb stiffness compared with males, although this investigation did not normalize data to body mass. To date, it has not been established whether sex differences in limb and joint stiffness exist during running and how they may potentially influence injury aetiology. The aim of the current investigation was to therefore determine whether female recreational runners exhibit distinct limb and joint stiffness characteristics in relation to their male counterparts. Such data may provide better understand on the increased prevalence of chronic lower extremity injuries in females.

\section{Material and methods}

Fourteen male (age 25.21 \pm 2.36 years, height 1.89 $\pm 0.11 \mathrm{~m}$, mass $77.47 \pm 5.16 \mathrm{~kg}$ ) and fourteen female (age $26.72 \pm 5.62$ years, height $1.66 \pm 0.15 \mathrm{~m}$, mass 62.37 $\pm 7.21 \mathrm{~kg}$ ) recreational runners took part in this investigation. All participants provided written informed consent and ethical approval was obtained from the University in line with the principles delineated in the Declaration of Helsinki.

The participants completed five running trials at $4.0 \mathrm{~m} \cdot \mathrm{s}^{-1} \pm 5 \%$. Lower extremity kinematics were quantified using an eight-camera motion analysis system (Qualisys Medical, Sweden) at a sampling rate of $250 \mathrm{~Hz}$. Participants struck an embedded force platform (Kistler 9281CA, Kistler Instruments, UK) sampling at $1000 \mathrm{~Hz}$ with their dominant foot [22]. The stance phase of running was determined as the time over which $>20 \mathrm{~N}$ of force in the axial direction was applied to the force platform [23].

The calibrated anatomical systems technique (CAST) was utilised to quantify knee joint kinematics [24]. To define the anatomical frames of the right foot, shank and thigh, retroreflective markers were positioned onto the medial and lateral malleoli, medial and lateral femoral epicondyles, calcaneus, $1^{\text {st }}$ metatarsal, $5^{\text {th }}$ metatarsal and greater trochanter. Carbon-fibre tracking clusters comprising four non-linear retroreflective markers were positioned onto the thigh and shank segments. The foot segment was tracked using the calcaneus, $1^{\text {st }}$ metatarsal and $5^{\text {th }}$ metatarsal marker positions. Static calibration trials were obtained with the participant in the anatomical position in order for the positions of the anatomical markers to be referenced in relation to the tracking clusters. The $\mathrm{Z}$ (transverse) axis was oriented vertically from the distal segment end to the proximal segment end. The Y (coronal) axis was oriented in the segment from the posterior to anterior. Finally, the X (sagittal) axis orientation was determined using the right hand rule and was oriented from the medial to lateral. Participants wore the same footwear throughout the trials (Saucony Pro Grid Guide II, Saucony, USA) in sizes 5-10 men's UK.

Retroreflective markers were digitized using Qualisys Track Manager in order to identify the markers and exported as C3D files to Visual 3D software (C-Motion, USA). Ground reaction force and retroreflective marker trajec- tories were filtered at 50 and $12 \mathrm{~Hz}$ using a low-pass fourth-order zero-lag Butterworth filter. Knee and ankle joint kinematics were calculated using an XYZ sequence of rotations (where $\mathrm{X}$ - sagittal plane, $\mathrm{Y}$-coronal plane and $\mathrm{Z}$ - transverse plane rotations) [25]. Newton-Euler inverse-dynamics were also adopted to allow knee and ankle joint moments to be calculated. Segment length, ground reaction force (GRF) and angular kinematics were utilized to quantify joint moment-segment mass. All kinematic waveforms were normalized to $100 \%$ of the stance phase and then the processed trials were averaged. Discrete kinematic measures from the knee and ankle data extracted for statistical analysis were 1) angle at footstrike, 2) peak angle, 3) joint angular excursion (representing the angular displacement from footstrike to peak angle) and 4) peak joint moment.

Limb stiffness $\left(\mathrm{kN} \cdot \mathrm{kg} \cdot \mathrm{m}^{-1}\right)$, vertical ground reaction force $\left(\mathrm{N} \cdot \mathrm{kg}^{-1}\right)$, joint moments $\left(\mathrm{Nm} \cdot \mathrm{kg}^{-1}\right)$, and joint stiffness $\left(\mathrm{Nm} \cdot \mathrm{kg} \cdot \mathrm{rad}^{-1}\right)$ parameters were normalized to body mass in accordance with Sinclair et al. [13] and Wannop et al. [26]. Estimation of normalized limb stiffness during running used a mathematical spring-mass model [8]. Limb stiffness was determined from the ratio of the peak vertical GRF to the maximum compression of the leg spring, which was calculated as the change in limb length from footstrike to minimum limb length during the stance phase $[27,28]$. The normalized torsional stiffness of the knee and ankle joints were calculated as a function of the ratio of the change in sagittal joint moment to joint angular excursion in the sagittal plane between the beginning of the ground contact phase and the instant when the joints were maximally flexed [11].

Sex differences in normalized limb and joint stiffness characteristics were examined using independent $t$ tests with significance accepted at the $p \leq 0.05$ level. Effect sizes were calculated using Cohen's $d$. In addition, linear regression analyses were adopted in order to determine the strength of the relationship between measurements of joint and limb stiffness. The data were screened for normality using a Shapiro-Wilk test. Statistical procedures were conducted using SPSS v22.0 (IBM SPSS, USA).

\section{Results}

Table 1 and Figures 1-3 present the normalized limb and joint stiffness parameters as a function of sex. The results indicate that normalized limb and knee joint stiffness parameters were significantly influenced by sex.

\section{Joint kinematics}

The results show that normalized peak knee moment was significantly larger in female runners, $t(26)=2.09$, $p \leq 0.05, d=0.82$ (Table 1 , Figure $1 b$ ). Knee excursion was shown to be significantly larger in males, $t(26)=2.21$, $p \leq 0.05, d=0.87$ (Table 1, Figure 1a). 
Table 1. Limb and joint stiffness characteristics as a function of sex

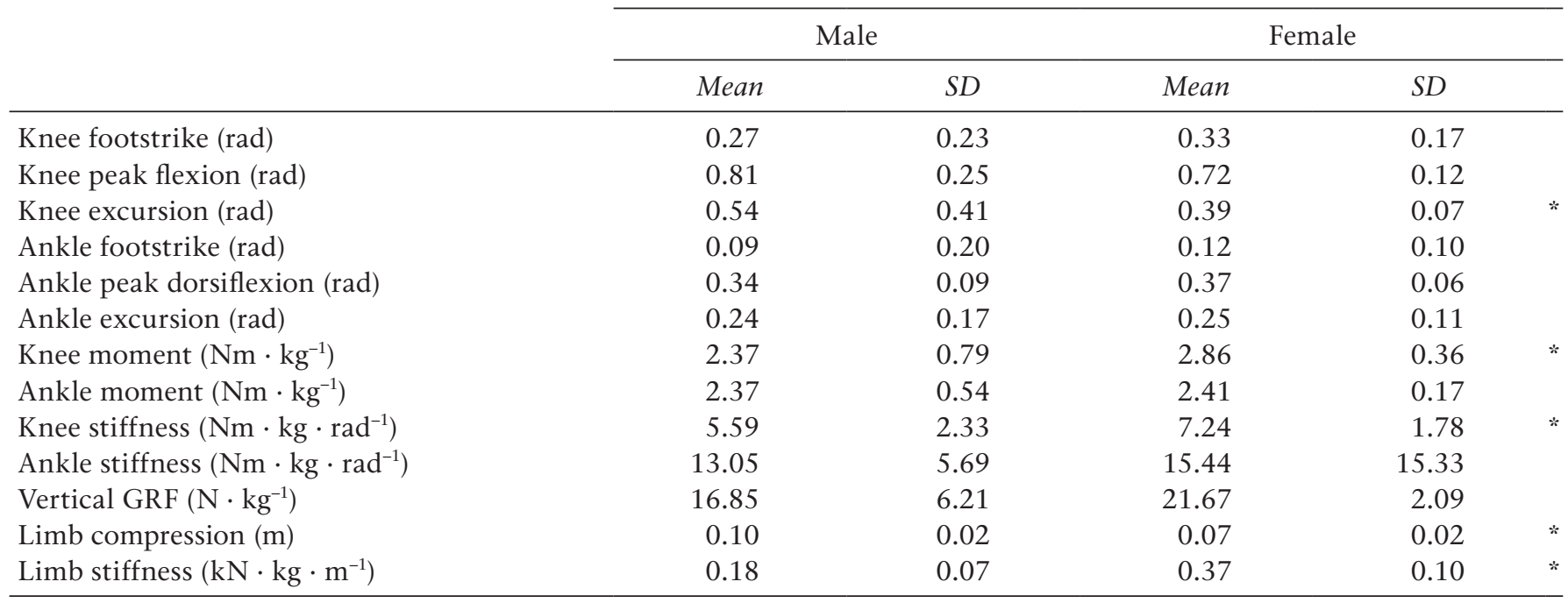

\footnotetext{
* significant difference
}
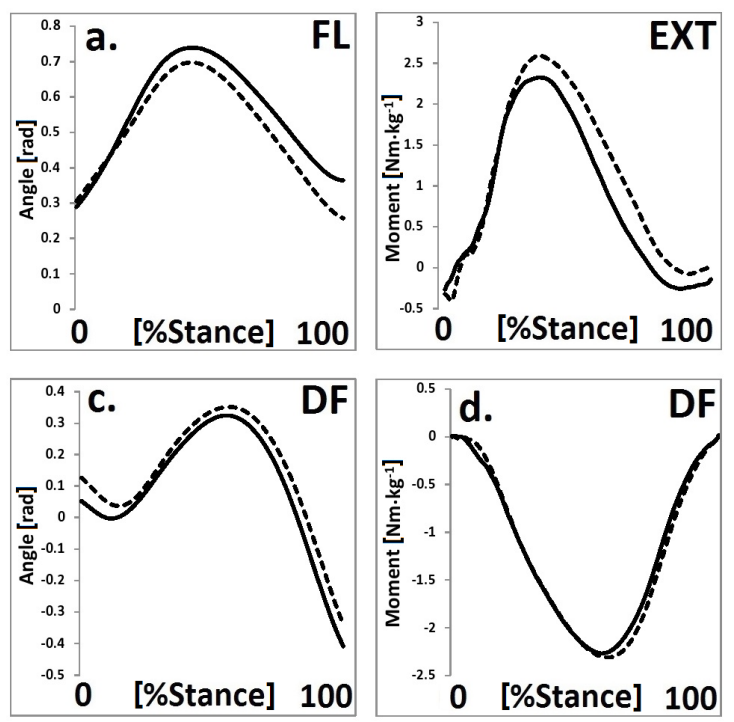

solid line - male, dashed line - female;

FL - flexion, EXT - extension, DF - dorsiflexion

Figure 1. Joint angles and normalized moments for sagittal knee angle (a), sagittal knee moment (b), sagittal ankle angle (c), sagittal ankle moment (d)

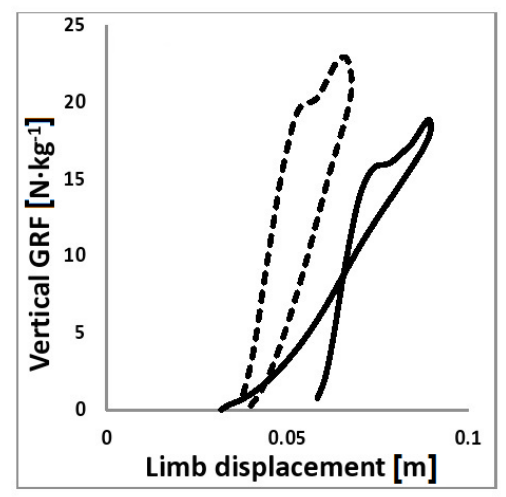

solid line - male, dashed line - female

Figure 2. Normalized vertical limb displacement curve (GRF)
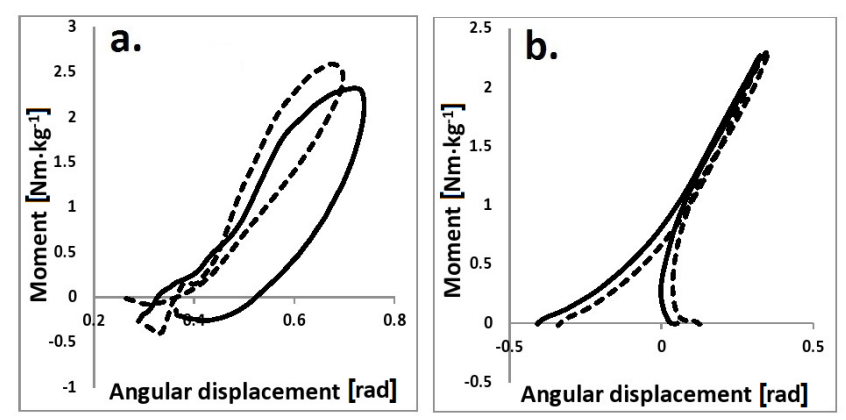

solid line - male, dashed line - female

Figure 3. Normalized knee (a) and ankle (b) joint moment-angular displacement curves

\section{Spring mass characteristics}

Normalized limb stiffness was shown to be significantly larger in female runners, $t(26)=5.40, p \leq 0.05$, $d=2.10$ (Table 1, Figure 2). Similarly, normalized knee stiffness was also shown to be significantly larger in females, $t(26)=2.10, p \leq 0.05, d=0.82$ (Table 1, Figure 3a). Limb compression was shown to be significantly larger in male runners, $t(26)=4.58, p \leq 0.05, d=1.80$ (Table 1 ).

\section{Correlational analyses}

Regression analysis revealed a significant positive association between normalized knee and limb stiffness $\left(R^{2}=0.44, p \leq 0.05\right)$.

\section{Discussion}

The current investigation determined whether female recreational runners exhibit distinct limb and joint stiffness characteristics in relation to their male counterparts. To the authors' knowledge, this represents the first 
investigation to examine sex differences in limb stiffness characteristics in recreational runners.

The first key observation is that normalized limb stiffness was found to be significantly larger in female runners compared with males. This observation opposes previous findings in hopping studies which have either shown a lack of differences between sexes or that males exhibited higher limb stiffness [20, 21]. It has been proposed that this difference relates to the different functional demands of hopping tasks in comparison with running [29]. This finding relates principally to the increase in limb compression between sexes as the normalized vertical GRF magnitude was shown to not differ significantly. This observation may have clinical relevance as increased levels of limb stiffness, such as those observed in female runners, have been linked to the aetiology of bone injuries [7, 12, 15, 16].

An additional important finding from the current study is that normalized knee stiffness was also shown to be significantly greater in female runners in relation to males. This finding is a reflection of the significant increase in normalized knee joint moment and significant reduction in knee joint angular excursion in female runners when compared with males. This observation concurs with those of Maliznak et al. [29] and Sinclair and Selfe [30], who found that females exhibited significantly reduced knee flexion excursion and normalized knee moment in comparison with males, and may also have possible clinical significance. Females have a far greater incidence of non-contact anterior cruciate ligament (ACL) injuries compared with males [31, 32]. Hewett et al. [32] proposed that females lack the neuromuscular control of sagittal plane musculature required to decelerate the centre of mass during landing; they limit knee flexion excursion and instead utilize passive restraints to a greater extent. The knee joint mechanics displayed by females are considered to increase their risk of ACL injury [31, 32].

The increase in peak normalized sagittal knee moment and knee stiffness may provide insight into the distinct injury patterns associated with female runners. Female recreational runners are at much greater risk of developing patellofemoral pain than age-matched males [6]. The significant increase in normalized knee joint moment and knee stiffness from the current study indicate that the load borne by the knee may be larger in female runners [18, 19]. Importantly, Hebert et al. [33] demonstrated that patellofemoral pain is a pathology related mainly to the knee extensor mechanism. Therefore, this finding may be important as the consensus regarding the aetiology of patellofemoral pain is that symptoms are a function of loading of the knee extensor mechanism $[34,35]$.

The increase in knee compliance in male runners may provide insight into the reduction in overall limb stiffness exhibited by males. The regression analysis revealed a significant positive association between knee stiffness and limb stiffness, indicating that knee compliance acts as a key regulator of limb stiffness. This is perhaps to be expected during running as the sagittal plane knee excursion is typically much larger than that of the ankle joint. Our results are in contrast with the observations of Farley and Morgenroth [11], who denoted that leg stiffness during submaximal hopping is primarily determined by the stiffness characteristics of the ankle joint. This discrepancy may relate to differences in the relative contribution of each joint to the distinct movements. It has been shown that the ankle joint is more crucial in hopping tasks when compared with running as it exhibits a larger sagittal plane excursion and is associated with a greater elastic behaviour of the plantar flexors $[11,35]$.

\section{Conclusions}

Although sex differences in running mechanics have been extensively examined, the current knowledge regarding sex differences in limb and joint stiffness parameters is limited. The present investigation therefore adds to the subject by providing a comprehensive evaluation of the limb stiffness characteristics of male and female recreational runners. On the basis that normalized knee and limb stiffness were shown to be significantly greater in female runners, the findings from the current investigation may provide further insight into the aetiology of the distinct injury patterns observed between sexes. Importantly, the findings from the current study support the notion that females are more susceptible to overuse injuries than males.

\section{References}

1. Lee D.C., Pate R.R., Lavie C.J., Sui X., Church T.S., Blair S.N., Leisure-time running reduces all-cause and cardiovascular mortality risk. Am J Coll Cardiol, 2014, 64 (5), 472-481, doi: 10.1016/j.jacc.2014.04.058.

2. van Gent R.N., Siem D., van Middelkoop M., van Os A.G., Bierma-Zeinstra S.M.A., Koes B.W., Incidence and determinants of lower extremity running injuries in long distance runners: a systematic review. Br J Sports Med, 2007, 41 (8), 469-480, doi: 10.1136/bjsm.2006.033548.

3. Taunton J.E., Ryan M.B., Clement D.B., McKenzie D.C., Lloyd-Smith D.R., Zumbo B.D., A prospective study of running injuries: the Vancouver Sun Run "In Training" clinics. Br J Sports Med, 2003, 37 (3), 239-244, doi: 10.1136/bjsm.37.3.239.

4. Sinclair J., Greenhalgh A., Edmundson C.J., Brooks D., Hobbs S.J., Gender Differences in the Kinetics and Kinematics of Distance Running: Implications for Footwear Design. Int J Sports Sci Eng, 2012, 6 (2), 118-128.

5. Grimston S.K., Ensberg J.R., Kloiber R., Hanley D.A., Bone mass, external loads, and stress fractures in female runners. Int J Sport Biomech, 1991, 7, 293-302.

6. Robinson R.L., Nee R.J., Analysis of hip strength in females seeking physical therapy treatment for unilateral patellofemoral pain syndrome. J Orthop Sports Phys Ther, 2007, 37 (5), 232-238, doi: 10.2519/jospt.2007.2439. 
7. Butler R.J., Crowell H.P., Davis I.M., Lower extremity stiffness: implication for performance and injury. Clin Biomech, 2003, 18 (6), 511-517, doi: 10.1016/S02680033(03)00071-8.

8. Blickhan R., The spring-mass model for running and hopping. J Biomech, 1989, 22 (11-12), 1217-1227, doi: 10.1016/0021-9290(89)90224-8.

9. Farley C.T., Gonzalez O., Leg stiffness and stride frequency in human running. J Biomech, 1996, 29 (2), 181-186, doi: 10.1016/0021-9290(95)00029-1.

10. Latash M.L., Zatsiorsky V.M., Joint stiffness: Myth or reality? Hum Mov Sci, 1993, 12 (6), 653-692, doi: 10.1016/0167-9457(93)90010-M.

11. Farley C.T., Morgenroth D.C., Leg stiffness primarily depends on ankle stiffness during human hopping. J Biomech, 1999, 32 (3), 267-273, doi: 10.1016/S0021-9290(98)00170-5.

12. Williams D.S., Davis I.M., Scholz J.P., Hamill J., Buchanan T.S., High-arched runners exhibit increased leg stiffness compared to low-arched runners. Gait Posture, 2004, 19 (3), 263-269, doi: 10.1016/S0966-6362(03)00087-0.

13. Sinclair J., Atkins S., Taylor P.J., The effects of barefoot and shod running on limb and joint stiffness characteristics in recreational runners. J Mot Behav, 2015, doi: 10.1080/ 00222895.2015.1044493. (Epub ahead of print)

14. Taylor P.J., Vincent H., Atkins S., Sinclair J., Acute exposure to foot orthoses affects joint stiffness characteristics in recreational male runners. Comparative Exercise Physiology, 2015, 11 (3), 183-190, doi: 10.3920/CEP150006.

15. McMahon J.J., Comfort P., Pearson S., Lower limb stiffness: considerations for female athletes. Strength Cond J, 2012, 34 (5), 70-73, doi: 10.1519/SSC.0b013e318268131f.

16. Bishop M., Fiolkowski P., Conrad B., Brunt D., Horodyski M., Athletic footwear, leg stiffness, and running kinematics. J Athl Train, 2006, 41 (4), 387-392.

17. Hamill J., Gruber A.H., Derrick T.R., Lower extremity joint stiffness characteristics during running with different footfall patterns. Eur J Sport Sci, 2014, 14 (2), 130-136, doi: 10.1080/17461391.2012.728249.

18. Laughton C.A., Davis I.M., Hamill J., Effect of strike pattern and orthotic intervention on tibial shock during running. J Appl Biomech, 2003, 19 (2), 153-168.

19. Hamill J., Moses M., Seay J., Lower extremity joint stiffness in runners with low back pain. Res Sports Med, 2009, 17 (4), 260-273, doi: 10.1080/15438620903352057.

20. Padua D.A., Carcia C.R., Arnold B.L., Granata K.P., Gender differences in leg stiffness and stiffness recruitment strategy during two-legged hopping. J Motor Behav, 2005, 37 (2), 111-126, doi: 10.3200/JMBR.37.2.111-126.

21. Granata K.P., Padua D.A., Wilson S.E., Gender differences in active musculoskeletal stiffness. Part II. Quantification of leg stiffness during functional hopping tasks. J Electromyogr Kinesiol, 2002, 12 (2), 127-135, doi: 10.1016/S10506411(02)00003-2.

22. Sinclair J., Hobbs S.J., Taylor P.J., Currigan G., Greenhalgh A., The Influence of Different Force and Pressure Measuring Transducers on Lower Extremity Kinematics Measured During Running. J Appl Biomech, 2014, 30 (1), 166-172, doi: 10.1123/jab.2012-0238.

23. Sinclair J., Edmundson C.J., Brooks D., Hobbs S.J., Evaluation of kinematic methods of identifying gait events during running. Int J Sports Sci Eng, 2011, 5 (3), 188-192.

24. Cappozzo A., Catani F., Croce U.D. Leardini A., Position and orientation in space of bones during movement:
Anatomical frame definition and determination. Clin Biomech, 1995, 10 (4), 171-178, doi: 10.1016/02680033(95)91394-T.

25. Sinclair J., Taylor P.J., Edmundson C.J., Brooks D., Hobbs S.J., Influence of the helical and six available Cardan sequences on 3D ankle joint kinematic parameters. Sports Biomech, 2012, 11 (3), 430-437, doi: 10.1080/14763141. 2012.656762.

26. Wannop J.W., Worobets J.T., Stefanyshyn D.J., Normalization of ground reaction forces, joint moments, and free moments in human locomotion. J Appl Biomech, 2012, 28 (6), 665-76.

27. McMahon T.A., Cheng G.C., The mechanics of running: how does stiffness couple with speed? J Biomech, 1990, 23 (Suppl. 1), 65-78, doi:10.1016/0021-9290(90)90042-2.

28. Hobara H., Muraoka T., Omuro K., Gomi K., Sakamoto M., Inoue K. et al., Knee stiffness is a major determinant of leg stiffness during maximal hopping. J Biomech, 2009, 42 (11), 1768-1771, doi: 10.1016/j.jbiomech.2009.04.047.

29. Malinzak R.A., Colby S.M., Kirkendall D.T., Yu B., Garrett W.E., A comparison of knee joint motion patterns between men and women in selected athletic tasks. Clin Biomech, 2001, 16 (5), 438-445, doi: 10.1016/S02680033(01)00019-5.

30. Sinclair J., Selfe J., Sex differences in knee loading in recreational runners. J Biomech, 2015, 48 (10), 2171-2175, doi: 10.1016/j.jbiomech.2015.05.016.

31. Ireland M.L., Anterior cruciate ligament injury in female athletes: epidemiology. J Athl Train, 1999, 34 (2), 150-154.

32. Hewett T.E., Myer G.D., Ford K.R., Heidt R.S. Jr, Colosimo A.J., McLean S.G. et al., Biomechanical measures of neuromuscular control and valgus loading of the knee predict anterior cruciate ligament injury risk in female athletes: a prospective study. Am J Sports Med, 2005, 33 (4), 492-501, doi: 10.1177/0363546504269591.

33. Hebert L.J., Gravel D., Arsenault A.B., Tremblay G., Patellofemoral pain syndrome: the possible role of an inadequate neuromuscular mechanism. Clin Biomech, 1994, 9 (2), 93-97, doi: 10.1016/0268-0033(94)90030-2.

34. Ho K.Y., Blanchette M.G., Powers C.M., The influence of heel height on patellofemoral joint kinetics during walking. Gait Posture, 2012, 36 (2), 271-275, doi: 10.1016/j.gaitpost.2012.03.008.

35. Fukashiro S., Komi P.V., Joint moment and mechanical power flow of the lower limb during vertical jump. Int J Sports Med, 1987, 8 (Suppl.), 15-21, doi: 10.1055/s-20081025699.

Paper received by the Editor: January 9, 2015

Paper accepted for publication: July 27, 2015

Correspondence address

Jonathan Sinclair

Centre for Applied Sport and Exercise Sciences

School of Sport Tourism and Outdoors

University of Central Lancashire

Preston, Lancashire

PR1 2HE, United Kingdom

e-mail: jksinclair@uclan.ac.uk 